\title{
вMJ Global Health The Primary Care Spend Model: a systems approach to measuring investment in primary care
}

To cite: Baillieu R, Kidd M, Phillips R, et al. The Primary Care Spend Model: a systems approach to measuring investment in primary care. BMJ Global Health 2019;4:e001601. doi:10.1136/ bmjgh-2019-001601

Handling editor Seye Abimbola

Received 1 April 2019 Revised 9 June 2019 Accepted 10 June 2019
Check for updates

(c) Author(s) (or their employer(s)) 2019. Re-use permitted under CC BY-NC. No commercial re-use. See rights and permissions. Published by BMJ.

For numbered affiliations see end of article.

Correspondence to Dr Robert Baillieu; rbaillieu@gmail.com

\section{ABSTRACT}

Increased investment in primary care is associated with lower healthcare costs and improved population health. The allocation of scarce resources should be driven by robust models that adequately describe primary care activities and spending within a health system, and allow comparisons within and across health systems. However, disparate definitions result in wide variations in estimates of spending on primary care. We propose a new model that allows for a dynamic assessment of primary care spending (PC Spend) within the context of a system's total healthcare budget. The model articulates varied definitions of primary care through a tiered structure which includes overall spending on primary care services, spending on services delivered by primary care professionals and spending delivered by providers that can be characterised by the '4Cs' (first contact, continuous, comprehensive and coordinated care). This unifying framework allows a more refined description of services to be included in any estimate of primary care spend and also supports measurement of primary care spending across nations of varying economic development, accommodating data limitations and international health system differences. It provides a goal for best accounting while also offering guidance, comparability and assessments of how primary care expenditures are associated with outcomes. Such a framework facilitates comparison through the creation of standard definitions and terms, and it also has the potential to foster new areas of research that facilitate robust policy analysis at the national and international levels.

\section{INTRODUCTION}

In the 40 years since the Declaration of Alma Ata, the evidence supporting strong links between improved primary care and more equitable outcomes has grown considerably. ${ }^{1}$ This is affirmed by the Declaration of Astana and also wide-ranging research that seeks to elucidate the optimal level of resources that should be allocated to the provision of primary care across health systems. ${ }^{2} 3$ But while such analyses codify the role of primary

\section{Summary box}

- Evidence related to primary care spending is limited by heterogeneity among definitions of primary care and by a lack of standardised methodologies to calculate primary care spend.

- This model articulates varied definitions of primary care through a tiered structure that reflects progressive health system sophistication and complexity, as this provides a method to more accurately assess and compare health systems.

- As the provision of health becomes more complex across states and institutions, a universal framework to describe spending and resource allocation is important.

- The model described in this paper facilitates comparison through the creation of standard definitions and language, which allows for universal descriptions of primary care spending within the context of an economic system's total health budget.

care in society and allow for comparative assessment, they also highlight challenges in characterising spending on primary care. As global spending on healthcare-especially in many high-income economies-continues to increase, there is a need to describe expenditure on primary care in a uniform way in order to enable comparisons and benchmarking, and to inform policy interventions and targets for ongoing investment in primary care.

The Primary Care Spend Model (PC Spend Model) described in this paper seeks to create standard definitions and language to facilitate universal descriptions of primary care spending within a system's total health budget. This approach has the benefit of describing how embedded primary care is within health systems, and has the potential to foster new areas of comparative research that facilitate robust policy analysis at the national and international levels. 
One of the barriers to a common definition of primary care spend is the range of interpretations as to what constitutes primary care. The WHO, for example, defines primary care as being first-contact care that is accessible at the time of need, and that is delivered in a coordinated, comprehensive and continuous manner. ${ }^{4}$ The Institute of Medicine expands on this to define primary care as being: 'integrated, accessible health care services by clinicians who are accountable for addressing a large majority of personal health care needs, developing a sustained partnership with patients, and practicing in the context of family and community. ${ }^{5}$ Starfield, however, simplifies the definition to: 'first-contact, continuous, comprehensive, and coordinated care provided to populations undifferentiated by gender, disease, or organ system., ${ }^{6}$ The Starfield definition encompasses continuous care across a patient's lifespan, and it has become known as the '4Cs of Primary Care'. This definition is now a standard by which high-performing primary care providers can be assessed.

Three states in the USA-Rhode Island, Oregon and Delaware-have defined primary care in policy, the former two as part of policies for increasing primary care spend. In Oregon, claims-based expenditures on services provided by primary care providers, as well as homeopathy and natural medicine providers, are combined with capitated or salaried expenditures, risk-based reconciliation, primary care medical home payments, health information technology and provider incentives to generate an assessment of spending. ${ }^{7}$ Rhode Island previously adopted a definition based on the "primary care provider'- 'the physician, practice or other medical practitioner who is considered to be an individual's usual source of care. ${ }^{, 8}$ In preparation for a primary care spend policy, Delaware defines a 'primary care provider' as being a 'physician, physician assistant, or nurse practitioner in family medicine, pediatrics, internal medicine or geriatrics who has initial contact with a patient. ${ }^{, 9}$ The variation across these three states is likely to be compounded as a dozen others are considering similar policies.

A 2017 report by Bailit and colleagues attempted to estimate primary care spend across private payers and promulgated two options: (1) a provider-based definition, regardless of location; and (2) a provider and service-based measure that encompasses office and outpatient-based services provided by any type of provider who undertakes primary care activities. ${ }^{8}$ Internationally, the Organisation for Economic Co-operation and Development (OECD), WHO and World Bank are similarly struggling with a lack of consensus on definitions, as they attempt to compare countries. In 2016, the OECD proposed that primary care spending be estimated in two ways, based on System of Health Accounts (SHA) catego$\operatorname{ries}^{10}$ : a narrow definition limited estimates to 'outpatient curative and rehabilitative care [excluding specialist care and dental care], home-based curative and rehabilitative care, ancillary services, and preventive services if provided in an ambulatory setting'; whereas a wider definition included estimates attributed to specialist care, and also 'total preventive services in all settings (including hospitals and long term care facilities)'. ${ }^{11}$

Variation in definitions can have wide estimate effects. The 2016 OECD report, for example, found that the 'narrow' definition of spending on primary care averaged around $12 \%$ of current health spending, ranging from $6 \%$ in Norway to $16 \%$ in Switzerland. Using the OECD's 'wider' definition, primary care spending averaged around $17 \%$ of health spending, with a range of $11 \%$ in Denmark to $34 \%$ in Mexico. Their report acknowledged that the 'narrow' definition was a better definition of primary care, but said that it was more difficult to administer because, for many countries, it was difficult to discern generalist outpatient from subspecialty outpatient spending. Moreover, some countries include preventative services, such as immunisations, in primary care estimates. ${ }^{11}$ This is further complicated by variation in how total health spending is measured. For example, some measures of total health spending exclude the cost of medications.

\section{THE PRIMARY CARE SPEND MODEL}

The PC Spend Model (In December 2017, the American Academy of Family Physicians' Robert Graham Center for Policy Studies and the American Board of Family Medicine hosted a methods conference in Washington DC, USA, on the measurement of primary care spending. The conference included international payment, policy and primary care experts who came together to discuss the development of a common definition of primary care spending to support country-level comparisons, to enable research on outcomes and to support policy development. The PC Spend Model described in this paper arose out of the conference proceedings) articulates varied definitions of primary care through a tiered structure that also supports measurement of primary care spending across nations of varying levels of economic development. The model recognises that primary care spending forms part of total health expenditure.

This three-part conceptual model (figure 1) distils primary care spending into core components that move from the percentage of money spent on the provision of essential community and primary care functions (Tier A), to the portion of primary care spending dedicated to the delivery of primary care services provided by ambulatory primary care providers (Tier B), and finally to the percentage of spending by those primary care providers that embody Starfield's idealised 4Cs of primary care (Tier C). In this way, the model offers increasing specificity at each level, and an ideal to which policymakers and countries can aspire. This approach also assists in understanding the manner in which resources are allocated, while also assessing the complexity of a health system's primary care environment.

Figure 2 provides a conceptual image of the PC Spend Model. Spending includes all government and private 


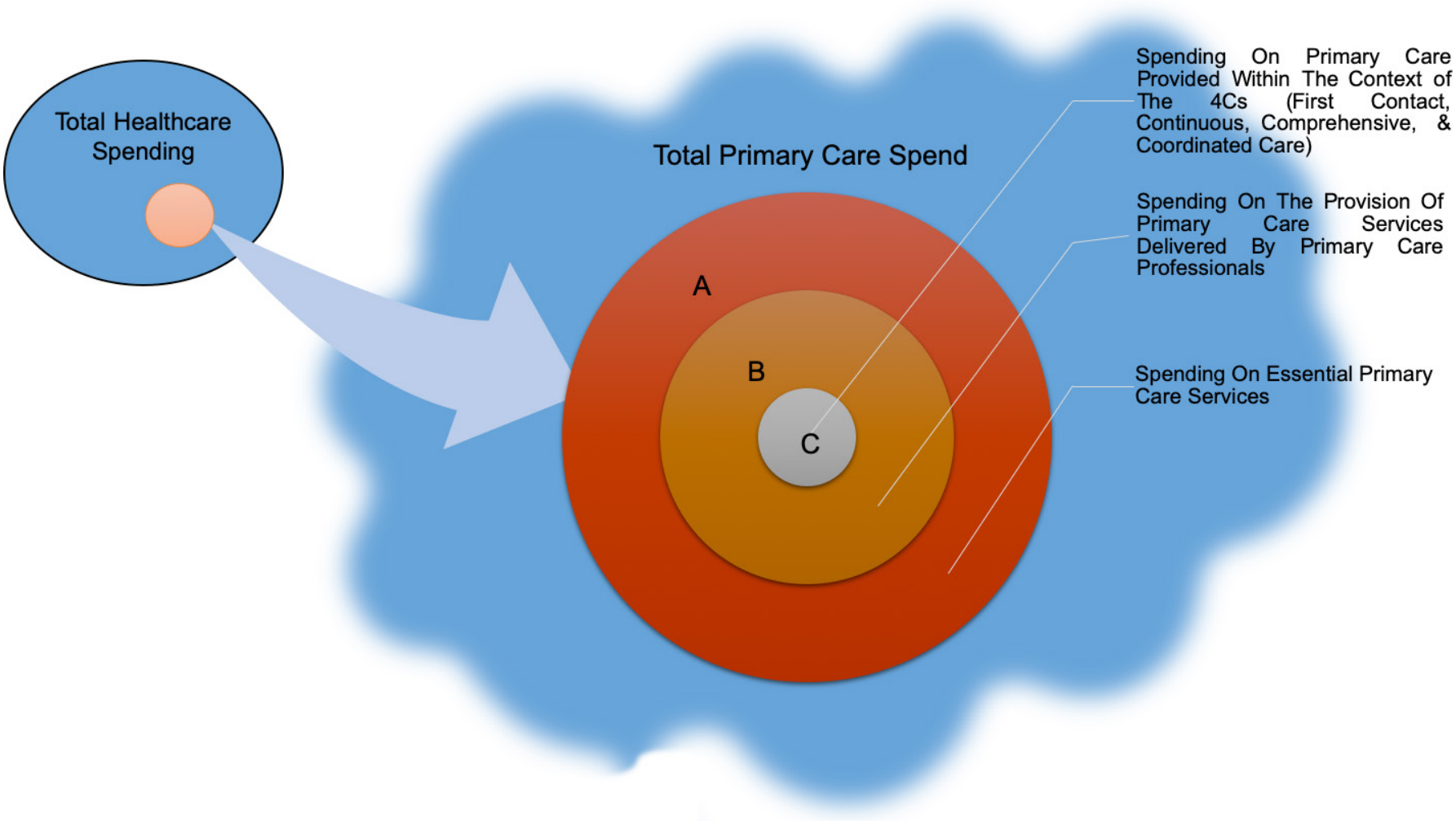

Figure 1 The constituent components of the Primary Care Spend Model.

payments to public and private providers. The largest and first level (Tier A) tracks expenditure on all essential, undifferentiated primary care services that occur at the community level. This may include all public health spending and primary care activities provided to a community by primary healthcare providers (HP), public health officials and community health workers. This tier offers a baseline for international comparisons, and it consolidates primary healthcare activities delivered at different sites, within a nation's healthcare system. Provision of healthcare under these circumstances potentially enhances access to primary care, since services are provided in a broad and undifferentiated manner.

The second level of the model (Tier B) estimates the portion of spending on activities undertaken by primary care providers, and includes the activities of family physicians and general practitioners, primary care nurses, community-based physician assistants and community-based nurse practitioners. This level allows for analysis of how direct spending on primary care providers impacts the health system, which can aid in creation of rational policy interventions. Further to this, the measure details the effectiveness of primary care activities when matched to measures of primary care outcomes, such as the rate of childhood vaccinations. Its weakness is that it does not differentiate robust from weak primary care delivery, the former of which is linked to desired outcomes.

The model's third level (Tier C) represents the percentage of spending on those services by providers who are delivering care according to 'Starfield's $4 \mathrm{Cs}$ '. This idealised view of primary care requires the infrastructure, payment systems and policy to support coordinated activities initiated by primary care physicians to care for patients in a longitudinal, continuous, coordinated and comprehensive manner. This model of care is sophisticated and, depending on the country, potentially more difficult to assess. It is, however, the ideal manner in which primary care providers deliver care and improve population health outcomes. ${ }^{12}$

\section{MEASUREMENT OF VARIABLES}

The use of data to estimate primary care spending across health systems is the subject of an evolving body of literature. A recent analysis by Vande Maele and colleagues ${ }^{13}$ elucidated that while the SHA 2011 is 'commonly used as the global standard in tracking health expenditure,' it does not offer simple primary care categories. Instead, components of primary care can be found in different SHA 2011 categories-namely the healthcare function (HC) and HP classifications. ${ }^{13}$ In their analysis, Vande Maele and colleagues determine that the HC classification better encapsulates first-contact primary care activities, but that estimation of expenditure using this category requires inferences about utilisation and volume. The provider category is noted to be problematic since primary care 'can be delivered in all settings. ${ }^{13}$

In contrast to the SHA 2011, the OECD 'Spending on Primary Care: First Estimates' uses proxy measures found in the Joint Health Accounts Questionnaire (JHAQ) to estimate the allocation of resources towards general primary care activities and also the provision of primary 


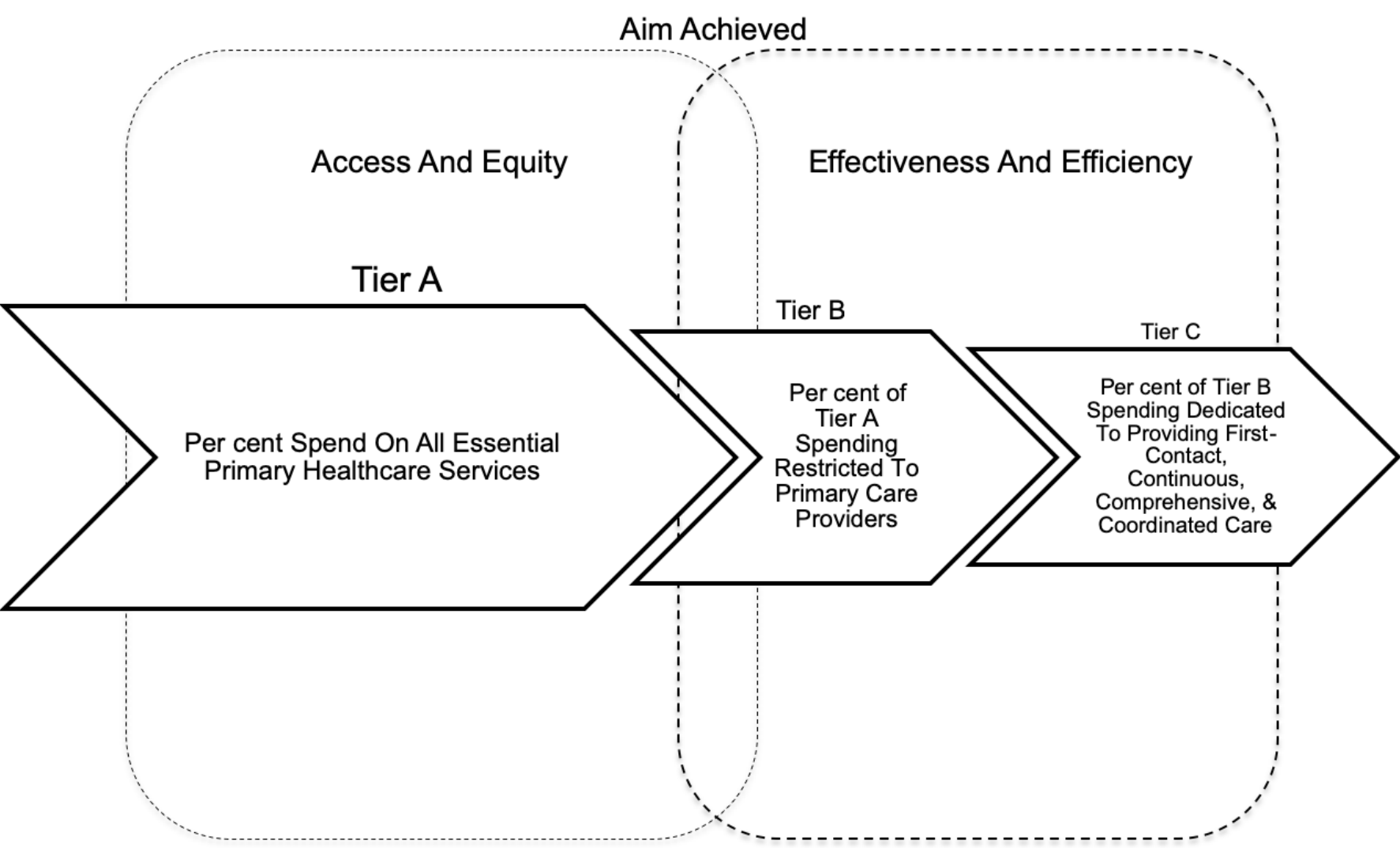

Feasibility of Measurement

\section{High}

\section{Sophistication of Health System Under Investigation}

Figure 2 Conceptual diagram of the Primary Care Spend Model.

care by providers. ${ }^{14}$ The JHAQ allows for estimates of spending by function (the type of service provided), by provider (the designation of an individual providing a service) and by financing schemes (the person or entity paying for the service). Of note, the OECD uses a wider set of activities and providers to estimate primary care spending, partially reflecting a lack of granularity in existing SHA classifications of services and providers which are not geared towards measuring primary care spending. The JHAQ provides data at the required level of detail to estimate spending on primary care across 22 OECD countries.

Starfield and Shi's 2002 study on "policy relevant determinants of health ${ }^{, 15}$ reported that no country at that time routinely collected data on practice characteristics that encompassed first-contact care, comprehensiveness, coordination and continuity. For the purposes of her analysis, Starfield undertook qualitative interviews to score the presence of these activities in various developed economies. In recent years, however, government mandates have created programmes, such as Medicare Advantage in the USA and Sustainability and Transformation Partnerships in the UK, that promulgate Starfield's 4Cs. In this way, there is increasing interest in promoting optimal primary care activities, and as programmes become more widespread, data will be generated. Currently, however, estimation of expenditure on the PC Spend Model's Tier $C$ requires qualitative assessment.

Figure 3 details the constituent components of the PC Spend Model and their related categories. For international comparison, the first two tiers of the PC Spend Model might be estimated using the JHAQ or widely available SHA 2011 data, since they relate to primary care function and providers. Estimation of Tier $\mathrm{C}$ poses more of a challenge since associated data are not routinely collected or disseminated in many healthcare systems. However, at the national or state level, local data can be applied to the model in order to create national, standard estimates of primary care expenditure that facilitate local comparison and also demonstrate how resources are 


\begin{tabular}{|c|l|}
\hline Tier A - Primary Care Functions & $\begin{array}{l}\text { Percentage of total health spending on all essential, undifferentiated primary } \\
\text { care services that occur at the community level. This may include all public } \\
\text { health spending and primary care activities provided to a community by } \\
\text { primary healthcare providers, public health officials and community health } \\
\text { workers. Activities in this category include: Health promotion and prevention; } \\
\text { Diagnosis, treatment, cure and rehabilitation services; Care of acute illness, } \\
\text { chronic illness and disability; Palliative care; and the provision of community } \\
\text { health programmes. }\end{array}$ \\
$\begin{array}{c}\text { Tier B - Primary Care Providers } \\
\begin{array}{c}\text { Tier C - Gold Standard Care Delivered in a } \\
\text { Conner Consistent with The 4Cs (First-Contact, }\end{array}\end{array}$ & $\begin{array}{l}\text { Percentage of total health spending on activities undertaken by primary care } \\
\text { providers, and includes the activities of family physicians and general } \\
\text { practitioners, primary care nurses, community-based physician assistants and } \\
\text { community-based nurse practitioners. }\end{array}$ \\
\hline Care) & $\begin{array}{l}\text { Percentage of total health spending on those services by primary care } \\
\text { providers who are delivering care according to "Starfield's 4Cs". }\end{array}$ \\
\hline
\end{tabular}

Figure 3 Elements of the Primary Care (PC) Spend Model and corresponding categories.

applied to primary care activities. This offers an advantage to policymakers who may wish to undertake analysis of how primary care activities impact health outcomes.

While variability in how economic systems assess and pay for primary care activities complicates expenditure assessments, the PC Spend Model represents an opportunity to test data sources and to carefully develop a set of international, standard data sets that yield detailed information about the allocation of resources towards primary care. The advantage of applying the PC Spend Model to the genesis of these data sets is that it considers varied definitions of primary care-reflecting global variation in how primary care is defined-while also allowing for the many places and methods by which primary care is delivered. Moreover, the model encourages consideration of primary care on a continuum from the community setting, to the more complex delivery of Starfield's $4 \mathrm{Cs}$ of primary care.

\section{APPLICATIONS OF THE PRIMARY CARE SPEND MODEL}

The PC Spend Model has the advantage of moving beyond a services-only perspective, as found in current SHA models, and describes the allocation of resources. While the PC Spend Model accounts for all primary care activities within a health system, its structure offers unique insights into how resources are applied to the provision of primary care. Indeed, the largest tier (demarcated as Tier A in figure 1) describes the foundation of primary care activities within a health system. These undifferentiated functions predominate in less advanced health systems, since they occur at the community level and are designed to improve overall population health. In more advanced systems, these activities support primary care providers as they deliver care to populations (Tier B). The PC Spend
Model estimates spending on these activities, and through categorisation, indicates how advanced primary care activities within a health system might be. Indeed, the model's third tier (Tier C) details the proportion of spending dedicated to the most sophisticated level of primary care- the provision of care according to Starfield's 4Cs. In this way, the PC Spend Model may help researchers and policymakers to better understand how structural components augment a system's health outcomes. This builds on work by the Primary Health Care Performance Initiative ${ }^{16}$ and the Primary Care Systems Profiles and Performance. ${ }^{17}$

The World Bank and the WHO have promulgated the importance of well-funded and well-structured primary care in fostering access to necessary services and care. ${ }^{18}$ This is considered fundamental to creating universal health coverage (UHC), which encourages improved community health, social justice and patient empowerment. Sustainable UHC requires infrastructure and networks of varied complexity and interconnectedness. The PC Spend Model's systems approach to analysing a nation's primary care structure yields information about the interdependence of components within a health system in a manner that might allow policymakers to better account for local complexity in health needs and primary care delivery. ${ }^{19}$ This suggests that the performance of primary care systems cannot be viewed in terms of its individual components or outcomes, but more in 'terms of related and underlying structures and processes that explain these outcomes. ${ }^{20}$ The PC Spend Model encourages an analysis of underlying structures and processes in a standardised manner. This facilitates a sophisticated comparison between health systems, and has with the potential to yield new insights into how individual health systems operate. 
While the PC Spend Model can describe primary care expenditure and structures in developed economies, it also has applications in low/middle-income countries where payment structures may not always be as well defined. This is because the model classifies activities on a spectrum within the context of total healthcare spending. Further to this, the model's tiered structure and reference to health system complexity offers an analytical approach to primary care activities or policy. This model allows researchers and policymakers an opportunity to identify where they fit within tiers of the PC Spend Model. The PC Spend Model can accommodate differences in definition while supporting analytical comparisons and testing for differences in outcome too.

A striking example of how the PC Spend Model might be used to assess resource allocation and the evolution of health policy can be found in Turkey's Health Transformation Plan (HTP). These widespread reforms were first enacted in 2003, and were designed to provide universal access to healthcare, financial risk protection, the promotion of patient rights, increased satisfaction among HPs and improved health outcomes. ${ }^{21} 22$ Prior to these reforms, it was estimated that Turkey spent $3.6 \%$ of gross domestic product (GDP) on healthcare-well below the OECD average of $7.4 \%$ of GDP. ${ }^{22}$

The backbone of the HTP was to increase the number of family physicians practising in Turkey, with primary care paid for by state insurance and provided in state-contracted Family Medicine Centers. ${ }^{23}$ This allowed for continuity of care, locally responsive health policy and oversight. Risk-adjusted, capitated payments encouraged physician migration to rural and underserved areas, while pay for performance initiatives encouraged widespread vaccination programmes. In this way, Turkey moved towards a greater level of Tier B spending, and made headway in improving access and equity, while also attempting to foster effectiveness and efficiency. These assertions are born out through the results of Turkey's health reform, which includes increased life expectancy, improved maternal and child health and widespread vaccination coverage. Figure 4 categorises the HTP reforms within the context of the PC Spend Model using extrapolation based on service-oriented outcome studies. ${ }^{21-23}$ This demonstrates the potential utility of depicting change in primary care activities and care delivery using the model.

\section{CONCLUSION}

The PC Spend Model recognises the importance of studying direct spending on primary care activities, and how the structure and complexity of health systems impact outcomes. It provides an opportunity to map primary care activities within a health system and to also create sophisticated comparisons that potentially yield new insights into how resources are applied to infrastructure and human capital. Furthermore, the model recognises that primary care contributes to the larger health system, and that primary care activities may be delivered by both publicly and privately funded physicians, and within institutions with multiple affiliations. In this way, the model creates a dynamic insight into a health system's primary

Primary Care Resource Allocation Prior To The Health Transformation Plan

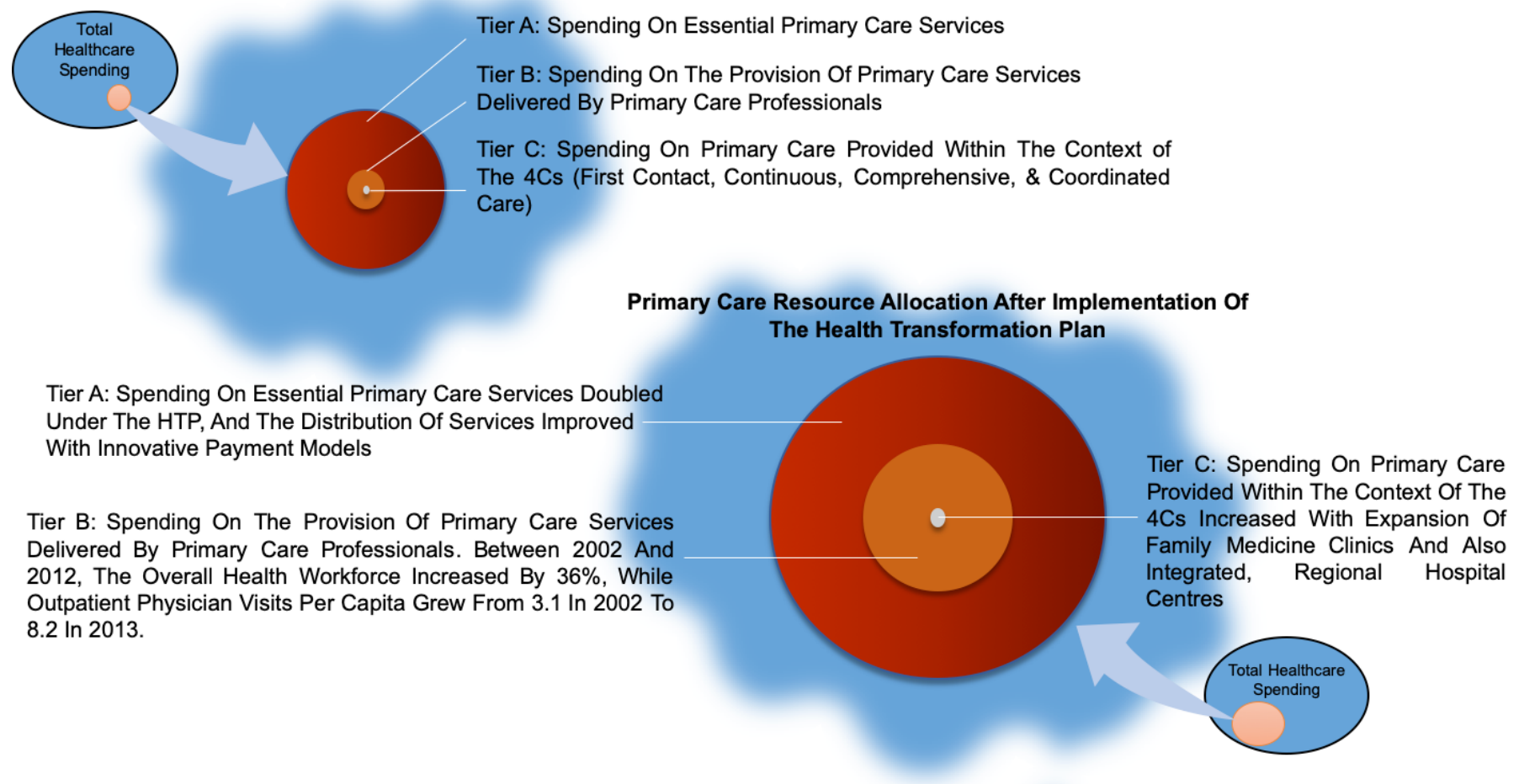

Figure 4 Turkey's Health Transformation Plan (HTP) reforms, categorised by the Primary Care (PC) Spend Model. 
care activities and how these form part of a broader system.

This model has broad applicability for policymakers and researchers who wish to compare health systems, and who also desire a novel way to assess the sophistication of a health system's primary care activities. The model's ability to provide insight into components of primary care spending may also be of interest to those health systems that are transitioning to universal healthcare, since this requires robust primary care systems. In this way, the PC Spend Model provides a new way to assess spending on primary care activities in increasingly complex economic and political environments that mandate accountability.

\author{
Author affiliations \\ ${ }^{1}$ The Robert Graham Center for Policy Studies in Family Medicine and Primary Care, \\ Washington, DC, USA \\ ${ }^{2}$ Department of Family and Community Medicine, University of Toronto, Ontario, \\ Canada \\ ${ }^{3}$ Center for Professionalism \& Value in Health Care, Lexington, Kentucky, USA \\ ${ }^{4}$ Cambridge Centre for Health Services Research, University of Cambridge Institute \\ of Public Health, Cambridge, UK \\ ${ }^{5}$ OECD Health Division, Directorate for Employment, Labour and Social Affairs, \\ Paris, France \\ ${ }^{6}$ Department of Health Care Policy, Harvard Medical School, Boston, Massachusetts, \\ USA \\ ${ }^{7}$ Department of Family And Community Medicine, Oregon Health and Science \\ University, Portland, Oregon, USA \\ ${ }^{8}$ Department of Family Medicine and Community Health, Duke University, Durham, \\ North Carolina, USA \\ ${ }^{9}$ The Bill and Melinda Gates Foundation, Seattle, Washington, USA \\ ${ }^{10}$ Department of Family Medicine and Population Health, Virginia Commonwealth \\ University, Richmond, Virginia, USA \\ ${ }^{11}$ Milbank Memorial Fund, New York City, New York, USA
}

Contributors All authors contributed equally to the creation of the PC Spend Model described in this paper. $\mathrm{RB}$ is responsible for planning and writing the manuscript. He was assisted in planning the manuscript by MK, RP, AB and MR. All other listed authors contributed to editing and augmenting the text of this manuscript.

Funding The American Board of Family Medicine Foundation and the American Academy of Family Physicians supported the Primary Care Spend Conference convening costs. Most US-based participants funded their own travel.

Competing interests None declared.

Patient consent for publication Not required.

Provenance and peer review Not commissioned; externally peer reviewed.

Data availability statement № additional data are available.

Open access This is an open access article distributed in accordance with the Creative Commons Attribution Non Commercial (CC BY-NC 4.0) license, which permits others to distribute, remix, adapt, build upon this work non-commercially, and license their derivative works on different terms, provided the original work is properly cited, appropriate credit is given, any changes made indicated, and the use is non-commercial. See: http://creativecommons.org/ licenses/by-nc/4.0/.

\section{REFERENCES}

1. Phillips RL, Bazemore AW. Primary care and why it matters for U.S. health system reform. Health Affairs 2010;29:806-10. (Millwood).

2. The World Health Organization. Declaration of Astana - global conference on primary health care, October, 2018. Available: https:// www.who.int/docs/default-source/primary-health/declaration/gcphcdeclaration.pdf

3. Dieleman JL, Templin T, Sadat N, et al. National spending on health by source for 184 countries between 2013 and 2040. The Lancet 2016;387:2521-35.

4. The World Health organization, regional office for Europe. main terminology. Available: http://www.euro.who.int/en/health-topics/ Health-systems/primary-health-care/main-terminology [Accessed 8 May 2019].

5. Davis K, Schoenbaum SC, Audet A-M. A 2020 vision of patientcentered primary care. J Gen Intern Med 2005;20:953-7.

6. Starfield B. Is primary care essential? The Lancet 1994;344:1129-33.

7. Oregon Health Authority,, Department of Consumer Business and Services. Primary care spending in Oregon - a report to the Oregon state legislature, February 2017. Available: http://www.oregon.gov/ oha/HPA/CSI-PCPCH/Documents/2017\%20SB231_Primary-CareSpending-in-Oregon-Report-to-the-Legislature.pdf [Accessed 6 Mar 2018].

8. Bailit MH, Friedberg MW, Houy ML. Standardizing the measurement of commercial health plan primary care spending. Milbank Memorial fund report, July 25, 2017. Available: https://www.milbank.org/ publications/standardizing-measurement-commercial-health-planprimary-care-spending/

9. Delaware Sof, Delaware Sof. State of Delaware. An Act To Amend Title 16,Title 18, And Title 29 Of The Delaware Code Relating To Primary Care Services, 2017. Available: http://delcode.delaware.gov/ sessionlaws/ga149/chp392.pdf [Accessed 20 Dec 2018].

10. OECD/Eurostat/WHO. A System of Health Accounts 2011: Revised edition. Paris: OECD Publishing, 2017.

11. Statistics OH. Definitions, sources and methods. Paris. 2016. France: Organization for Economic Co-operation and Development, 2016.

12. van Lieshout J, Wensing M, Campbell SM, et al. Primary care strength linked to prevention programs for cardiovascular disease. Am J Manag Care 2009;15:255-62.

13. Vande Maele N, Xu K, Soucat A, et al. Measuring primary healthcare expenditure in low-income and lower middle-income countries. BMJ Glob Health 2019;4:e001497.

14. OECD 2018, spending on primary care - first estimates. Available: http://www.oecd.org/health/health-systems/Spending-on-PrimaryCare-Policy-Brief-December-2018.pdf

15. Starfield B, Shi L. Policy relevant determinants of health: an international perspective. Health Policy 2002;60:201-18.

16. The primary health care performance initiative - about us. Available: https://phcperformanceinitiative.org/about-us/about-phcpi [Accessed 24 Sep 2018].

17. Alliance for health policy and systems research. Report of the expert consultation on primary care systems profiles and performance (PRIMASYS), July. 2015. Available: http://www.who.int/alliancehpsr/projects/PRIMASYS_Expert_Consultation_Final_Report.pdf [Accessed 24 Sep 2018].

18. Bank W. Tracking universal health coverage: 2017 global monitoring report (English. Washington, D.C: World Bank Group, 2017

19. Katerndahl $D$, Wood R, Jaen CR. Measuring interdependence in ambulatory care. J Eval Clin Pract 2017;23:453-9.

20. Alliance for health policy and systems research. Report of the expert consultation on primary care systems profiles and performance (PRIMASYS). Geneva, Switzerland. page 20, July. 2015

21. Akinci F, Mollahaliloğlu S, Gürsöz H, et al. Assessment of the Turkish health care system reforms: a stakeholder analysis. Health Policy 2012;107:21-30.

22. Baris E, Mollahaliloglu S, Aydin S. Healthcare in Turkey: from laggard to leader. BMJ 2010;342.

23. Sparkes SP, Bump JB, Reich MR. Political strategies for health reform in Turkey: extending veto point theory. Health Systems \& Reform 2015;1:263-75. 